\title{
El Padre de la perversa. Antígona materna en la poética de Gabriela Mistral
}

\section{Resumen}

Licia Fiol-Matta, en su libro A Queer Mother for the Nation, explica la relación entre la identidad queer de Gabriela Mistral y su apropiación por los distintos proyectos estatales de la época. Sostiene que el discurso político de la maternidad en Gabriela Mistral tiene consecuencias privatistas en último término. "Antígona", breve poema de Lagar II, sirve para reinterpretar la maternidad mistraliana desde una óptica diferente. En lugar del sujeto narcisista y paranoico que nutre el relato de Fiol-Matta propongo la perversión como un concepto más adecuado para articular las esferas de lo público y lo privado en la obra y figura de la poeta. En este sentido, la madre sería el soporte de la fantasía del Estado.

Palabras claves maternidad mistraliana, perversión, estudios mistralianos, Antígona

\begin{abstract}
In her book A Queer Mother for the Nation, Licia Fiol-Matta explains the relationship between Gabriela Mistral's queer identity and its appropriation by the multiple state projects of her era. She argues that the political discourse of maternity in the poet's writing has, in the last instance, privatizing consequences. "Antígona", short poem of Lagar II, can be used to reinterpret Mistralian maternity from a different perspective. I propose that perversion is a more appropriate concept to articulate the public ans private spheres in Mistral, than the narcissistic and paranoid subject of Fiol-Matta's narrative. In this sense, the mother is the bearer of the State's fantasy.
\end{abstract}

Keywords mistralian maternity, perversion, mistralian studies, Antigone

Gabriela Mistral es parte del lenguaje político de Chile. Urdida en libros escolares, estampada en un billete, consagrada en centros culturales y colegios. El rostro y la letra de la nación tienen el severo perfil de su nombre. Pero su imagen es más una trinchera que la transparente efigie de la nación. Licia Fiol-Matta, en 
su libro A Queer Mother of the Nation, pretende explicar la peculiar relación de Gabriela Mistral con el Estado. Afirma el estatuto queer de la poeta y su uso por los proyectos nacionalistas de Latinoamérica desde la construcción poética de la maternidad. A mi juicio, Fiol-Matta retorna a la misma separación entre la Mistral pública y la privada que, en un principio, pretende negar. En su relato, el momento político de Mistral se vincula a la identificación con el proyecto del Estado nacional en la forma de "Madre de la nación"; su relativización y posterior renuncia hacia una maternidad narcisista obliga a confinarla a la paranoia. Una lectura de "Antígona" de Mistral permite reinterpretar su obra y figura desde otra estructura, la perversión. Otorgar el estatuto de perversa a la maternidad mistraliana permite dinamizar la articulación de lo público y lo privado en los textos de la poeta, un cruce que revitaliza la posibilidad de comprenderla en el marco de una práctica política radical.

\section{II}

A Queer a Mother for the Nation muestra la paradójica construcción de la figura de Mistral en relación al sujeto Estatal. La identidad de Mistral es inestable frente a las categorías raciales, genéricas y sexuales del discurso estatal de la época, sin embargo, sirve a su reproducción. Su imagen masculinizada se entrelaza con la posición icónica de Madre latinoamericana. En este sentido, la articulación que hace Mistral entre su participación en la esfera pública y su vida privada es queer o rara. Siguiendo a David Halperin, “'queer is by definition whatever is at odds with the normal, the legitimate, the dominant. There is nothing in particular to which it necessarily refers. It is an identity without an essence" (62). La tensión gira en torno a su identificación con la maternidad. Mistral es identificada públicamente como "Madre de la nación" latinoamericana. Acoge el discurso del mestizaje, influencia de José Vasconcelos, quien la invita a participar del proyecto revolucionario en México. No obstante, nunca pare un hijo ni asume las prácticas de la familia heterosexual. Se retrata a sí misma como una 
madre con el destino incumplido de la reproducción. Se arroga la maternidad de Yin Yin, pretendido hijo adoptivo, pero siempre asegura su filiación imperfecta, no biológica. Además, comparte su vida doméstica con asistentes y secretarias, presumidas parejas lésbicas.

Se puede analizar el relato de Fiol-Matta en tres momentos. Primero, Mistral en Chile empleada en la burocracia estatal como maestra de escuela primaria ligada a la educación de las mujeres. Según Fiol-Matta, en esos años Mistral consagra su imagen de maestra y, en particular, la capacidad para reproducir el discurso dominante de las élites chilenas. Segundo, la internacionalización de Mistral a través del viaje que realiza a México, invitada por el Ministro de Educación José Vasconcelos. La influencia del intelectual mexicano desplaza el talante blanco del discurso público de Mistral hacia el mestizaje. Así, Mistral proyecta su profesión en terrenos más sólidos. La pose queer de la maestra resultaba incómoda para las mujeres de la élite chilena, acostumbradas al trato prescrito socialmente para el "sexo débil." Molestaban sus atavíos masculinos, su prosa política, su verso enrarecido. En cambio, una madre inusual, masculinizada, puramente espiritual, se acomodaba al proyecto mexicano, lo que permite a Mistral identificarse con el poder masculino. Asegura la crítica,

Instead of becoming the white doyenne of women's education, which she would have been destined to be if she had remained in Chile, Mistral became the national mother of racially mixed children. Mistral's unrealized biological motherhood would have plagued her in Chile, marking her as queer, yet it was perfectly suited to the Mexican endeavor. Racial others would seem to betray the conception of nationality in terms of biological intimacy, yet they had to be recruited into a state project increasingly articulated in terms of familial ties among all. Thus, the adoptive or "spiritual" model suited this state need quite effectively. (Fiol-Matta 68) 
Tercero, la tormentosa maternidad adoptiva de Yin Yin y su ulterior suicidio, sumado a la apoteosis del Premio Nobel. En términos de Fiol-Matta, Gabriela Mistral da un giro narcisista hacia una maternidad no utilitaria. Relativiza el compromiso con el proyecto nacional y su identificación con el Estado. Por tanto, vuelca su escritura hacia la experiencia corporal e íntima de la maternidad.

Fiol-Matta marca el paso entre el momento nacional y su posterior distanciamiento narcisista en dos textos. Uno, "Palabras de la extranjera", prólogo a Lectura para mujeres, libro que el mismo Vasconcelos comisiona a Mistral como texto guía para las niñas de la escuela que le estaba encargada. El otro, "Colofón con cara de excusa", incluido en la edición final de Ternura publicada en 1945. Fiol-Matta reconoce en ambos momentos una privatización de la agencia femenina. Mientras que en "Palabras de la extranjera" la mujer es confinada a la explotación estatal de su función reproductiva, en "Colofón con cara de excusa" la realización de la mujer abandona lo público y la desplaza hacia el reino de lo personal. Explica la autora, "Whereas the first essay, strictly speaking, is nationalist, reproducing nationalism's classic treatment of women, the second is narcissistic, exposing some of nationalism's dependency upon a paranoid state where all subjects are preoccupied with their extinction in the context of "national belonging"” (93).

Acceder al relato de Fiol-Matta no implica aceptar su explicación de los tránsitos de Mistral. Si lo que se intenta defender es el carácter queer de la relación entre la poeta y el Estado, sus conclusiones parecen implausibles en último término. A Queer Mother for the Nation retrata una Mistral estratega, políticamente lúcida, que se identifica con diversas funciones dentro del entramado simbólico del Estado de acuerdo a su conveniencia, separada de su fuero interno, en el que presenta una identidad agobiada por persecuciones imaginarias contra ella, proyectadas en el suicidio de Yin Yin, presunto homicidio y castigo divino a ojos de la madre. Así, el retorno de la separación estricta entre 
lo público y lo privado en la vida de Mistral oblitera la movilidad del sujeto queer. La misma erudición de Fiol-Matta quizá tribute una solución. Rastrea la subjetividad de Mistral a través de una enorme cantidad de archivos y documentos, entre ellos cartas, fotografías y los mismos textos literarios. El lazo social del paranoico, derivado de su narcisismo, lo ubica completamente fuera de las instituciones. Su interacción con el orden simbólico es puramente instrumental. Todo es un potencial ataque del mundo exterior a su ego, "Paranoia need not be only the state of mind wherein the individual fears annihilation by the malfeasance of another. Paranoia can also be the resulting psychic state of too much surveillance, visibility, encoding, and representing"(102). De ahí que Mistral genere un closet u ocultamiento en un significante ajeno, la maternidad. Dice Fiol-Matta, "Enforcing the stricture of belonging entailed a submerged but no less potent role for Mistral's "silent" sexuality. As I have discussed elsewhere, the language of reproduction and child care functions as a kind of closet that paradoxically has made public what was to remain private" (4).

Mistral exhibe una masculinidad femenina públicamente. Fiol-Matta documenta latamente esta pose con imágenes de apariciones públicas de la poeta, en la que se muestra semejante a sus contrapartes políticas masculinas. Mistral nunca declara explícitamente nada. Aunque pareciera que todo el mundo conoce el contenido de ese silencio, no obstante, permanece omitido. La misma FiolMatta lo formula en términos de visibilidad, "Mistral, as stereotype, became so visible as the nonmother that this fact became invisible; or, more precisely stated, it was disavowed. This idea can be represented thus: 'We know that Mistral is queer, but for us she is the Mother of America"” (48). En este sentido, en lugar de una forclusión psicótica, productora de un delirio paranoico, encontramos el mecanismo de la desmentida. El psicótico cree que su palabra siempre es efectiva en el mundo. Lo que nombra se hace real en su consciencia. El juego de Mistral, en cambio, responde a una estructura perversa. Mistral actúa la fantasía del Otro, pero conoce los límites de esta performance. Según Lacan, en la perversión el sujeto se pone en la posición del "objeto a", el objeto que produce el deseo. 
Mistral ocupa este lugar para el Estado, cuyo deseo es producir un tipo de maternidad a la que la escritura de Mistral da vida. Simultáneamente, este gesto implica mostrar la debilidad del Estado, del padre simbólico al que pretende consolar. Antígona será la clave para vislumbrar esta diferencia.

III

"Me conocía el Ágora, la fuente/ Dircea y hasta el mismo olivo sacro,/ no la ruta de polvo y de pedrisco/ ni el cielo helado que muerde la nuca/ y befa el rostro de los perseguidos" (1-5). Así comienza "Antígona", un breve texto de Lagar II, poemario póstumo de la poeta. Mistral imita su voz en tránsito a Colono, por los campos escarpados, nostálgica de Tebas y su pueblo. Mistral escoge Edipo en Colono, última tragedia de Sófocles, en la que el rey incestuoso se dirige hacia su última empresa. Sentado en una roca recibe signos del inminente arribo de la muerte. Llega a la villa de Colono junto a Antígona e Ismene, declara la fatalidad para su prole masculina y acaba en una tumba desconocida de la que únicamente una persona en el mundo tiene conocimiento. ¿Por qué Mistral fija sus ojos en esta tragedia? ¿Por qué leer a Mistral desde este margen? ¿Qué ilumina ese nombre entre tantos otros que la poetisa canta en su vasta producción? No escoge a la rebelde aristócrata que niega toda herencia por el nombre de su hermano, sino a la hija que escolta obsecuentemente al Padre.

Lacan realiza un gesto similar. Personifica a Antígona, pero desde el ademán perceptiblemente radical. En el Seminario 7 repite su voz:

Mi hermano es todo lo que ustedes quieran, el criminal, quiso arruinar los muros de la patria, llevar a sus compatriotas a la esclavitud, condujo a los enemigos al territorio de la ciudad, pero finalmente, él es lo que es y aquello de lo que se trata es de rendirle los honores fúnebres. Sin duda, no tiene el mismo derecho que el otro, puede contarme al respecto todo lo que quiera, que uno es el héroe y el amigo, que el otro es el enemigo, pero yo le respondo que poco me importa 
que abajo esto no tenga el mismo valor. Para mí, ese orden con que osa intimarme no cuenta para nada, pues para mí, en todo caso, mi hermano es mi hermano. (334)

La Antígona de Lacan y sus epígonos sublima al hermano, muestra la eficacia del significante. Polinices, nombre del hermano criminal, debe recibir los mismos honores que Eteocles, nombre del hermano heroico, aunque sea el enemigo de la ciudad, y lleve la polis a la destrucción. Para Antígona Polinices existe en la forma de un significante. Carente de cuerpo, lo que persiste es su nombre, ese ruido inagotable que puede provocar la debacle del orden civil. Puesto que está transfigurado en un nombre puro, Polinices merece los honores. Cuando declara un deseo que está más allá de la Ley, se convierte en el sujeto, la portadora, del deseo del gran Otro, del orden simbólico institucional, cuya voz es Creonte. Así, se transforma en el límite del Otro, mostrando que ninguna legalidad cumple con el bien político que promete por completo. Antígona enfrenta la satisfacción de su deseo que en lugar de apuntar a un bien, se dirige a la consecución de un goce excesivo al que no le importa la subsistencia de la ciudad ni la propia.

La Antígona de Mistral, en cambio, no solo se vincula al Padre, sino que sustenta su deseo llevándolo hasta la fatalidad que él mismo escogió. Es ella la marca de la fortaleza perdida. Escribe Mistral, "Yo era Antígona, brote de Edipo,/ y Edipo era la gloria de la Grecia" (15-6). Antígona es el lazarillo del ciego, el soporte que permite al arruinado rey de Tebas desafiar el último límite de su deseo. Se transforma ella misma en el falo, en lo que sutura la falta en el Otro. En este sentido, Antígona responde a la estructura del perverso.

La perversión es consecuencia de una falla en la función paterna. ${ }^{1}$ El perverso ha sido expuesto a una primera represión, se distingue del cuerpo de la madre, pero rechaza el tránsito al orden simbólico por la castración. El

${ }^{1}$ Seguiré la explicación de Fink en su artículo "Perversion", adoptando la contraposición del neurótico al perverso. 
mecanismo de defensa del perverso ante la posible pérdida del goce es desmentir la falta, imaginando una madre fálica. El perverso advierte la falta en el Otro; sin embargo, dado que no tiene acceso a perderse en el fantasma, se pone a sí mismo en el lugar del falo. De este modo, ocupa el lugar del objeto a del que el Otro, ocupando el lugar del sujeto, extrae su goce. Si la fórmula de la sublimación describe un objeto que adquiere la dignidad de lo Real, en la perversión, en cambio, la adquirirá el sujeto.

El perverso intenta reproducir la escena imposible de la castración, que permite nombrar el deseo de la madre mediante el uso de significantes, pero al nunca haber ingresado al orden simbólico la carencia del perverso lo obliga a regular su goce de manera inversa. Como no se puede valer del Nombre-delPadre, lo invoca a través de la transgresión. El acto perverso desplaza significantes, utilizándolo para fines diferentes de los determinados por el orden simbólico. El perverso privado de Ley se convierte en el agente de la fantasía del Otro, en una búsqueda incesante por ser castrado y que la prohibición sea pronunciada. La empresa del perverso se construye alrededor de esta demanda. El perverso representa en la realidad lo que el neurótico solo soporta en el fantasma. $\mathrm{Su}$ goce, paradójicamente, está en la misma Ley que intenta transgredir, en el Padre.

Este es el proceso que subyace a los héroes sádicos y al mismo Creonte. Ambos intentan sobrepasar el límite que la Antígona de Lacan hace explícito, tratan de llevar a sus víctimas a lo que Lacan llama una segunda muerte. No basta con el asesinato, el sádico goza con la imagen de un sufrimiento eterno, una muerte tan absoluta que absorbe el significante. Al igual que Creonte con el nombre de Polinices, el sádico desmiente su capacidad para exterminar el significante. Por esto, las víctimas en los relatos de Sade aparecen eternamente bellas, sin importar los abusos de su torturador. Diría Lacan, tienen la radiante belleza del significante. 
Y, en el caso de Antígona, ¿quién es la víctima de la hija perversa? $\mathrm{Su}$ propio cuerpo. La Antígona mistraliana, soportando al Padre ciego, responde a la estructura de la perversión femenina, lo que Kristeva identifica con la madre virgen, la madre fálica, no castrada. Mientras que el sujeto perverso masculino se goza en la proliferación sin fin de los objetos de su deseo que excitan en él la esperanza de convertirse en objeto del deseo del Otro, la perversión femenina "se acurruca en el deseo de la ley como deseo de reproducción y continuidad, promueve el masoquismo femenino al rango de estabilizador de la estructura (frente a sus desviaciones) y, por la seguridad que procura a la madre entrar así en el orden que sobrepasa la voluntad de los humanos, le da su prima de placer" (Kristeva 229).

Sin embargo, no es tan simple poner a Antígona en el lugar de la madre. ${ }^{2}$ Hay que delimitar la extensión que esta atribución adquiere en la obra de Mistral. Motivos de San Francisco, obra en prosa de la poeta, empieza con un canto de alabanza a la madre del santo. Para Mistral la madre, esta "María italiana", es la responsable por la existencia beatífica de San Francisco. Conforma el cuerpo del niño Francisco en una imagen plena de belleza, “. . . tú le hiciste con tus harinas esos dientecillos finos y blancos que le daban una sonrisa feliz; tú le pusiste la rica sangre que en su corazón se hizo tremenda caridad; muchas líneas de su cuerpo serían tuyas, y puede llamársete por esto "Copa de Dios"” (568); además, le da la lengua, "tú le enseñaste a hablar" (568-9); y afianza el sistema de valores desde los que se fundan las condiciones de su santidad, "tú, cristiana, le deslizaste en los siete años dóciles de la infancia a tu Cristo" (569). Biología, lengua y religión se unen en una sola herencia. La virgen, la madre del santo y Antígona

\footnotetext{
${ }^{2}$ Judith Butler advierte las consecuencias ideológicas de esta identidad. En el caso de Hegel, la más reconocida de estas interpretaciones, Antígona queda reducida a afirmar la familia, manifestación de las relaciones de parentesco, en oposición al Estado como comunidad ética que la subsume. Dice Butler, "Antigone emerges as a figure for Hegel in the Phenomenology only to become transfigured and surpassed in the course of Hegel's description of what she does. For Hegel, however, Antigone passes away as the power of the feminine and becomes redefined as the power of the mother, one whose sole task within the travels of Spirit is to produce a son for the purposes of the state, a son who leaves the family in order to become a warring citizen. Thus citizenship demands a partial repudiation of the kinship relations that bring the male citizen into being, and yet kinship remains that which alone can produce male citizens" (12).
} 
sosteniendo a Edipo, todas comparten el mismo goce: parir a su propio Padre. Es así como la madre mistraliana, lejos de asimilarse a la madre primigenia, se identifica con la función del límite de lo simbólico. Si el deseo, en el psicoanálisis lacaniano, es metonimia del ser, entonces bien podemos leer la perdida de la maternidad biológica y el matrimonio en el lamento de Antígona como la forma en la que se configura su demanda. Declara la perversa, "Iban en el estío a desposarme,/ iba mi pecho a amamantar gemelos/ como Cástor y Pólux, y mi carne/ iba a entrar en el templo triplicada" (10-3). Antígona pierde las posiciones de madre y esposa para el resto de los ciudadanos y se entrega por completo a Edipo. El psicótico diluye las distinciones entre el orden imaginario, simbólico y Real. Antígona psicótica sería Edipo, Yocasta y la hija de ambos, al mismo tiempo. En cambio, Antígona perversa se triplica en hija, madre y esposa del Padre. He ahí su transgresión.

IV

En Trouble with Strangers, Terry Eagleton narra una historia de la ética organizada desde las tres tópicas lacanianas. Ante Antígona, Eagleton señala el contraste en la lógica política que subyace en las tragedias de Sófocles:

The Sophocles whom Lacan so admires is scarcely at one with his own political scepticism. To turn from Antigone or Oedipus the King to Philoctetes and Oedipus at Colonus is to encounter a very different species of politics - one in which the adamancy of an Antigone is finally overcome, as the sacred powers of the obdurate self-exile are harnessed to the task of repairing the polis. (149)

La elección de Mistral de Edipo en Colono admite la pregunta ¿Qué tipo de acción colectiva sugiere la apropiación específica de Antígona en los textos de Mistral? Y su corolario, siguiendo el argumento de este ensayo, ¿Cómo genera una política la maternidad mistraliana? 
"Sobre la mujer chilena", texto de 1946, es un escrito de posguerra. La letra abatida de Mistral se refugia en la fantasía de una casa hundida en la cordillera. A esta casa "dejada de Dios y de los hombres" llega un intruso y toca la puerta. Una mujer recibe al hombre inmundo y bestializado. Lo viste, le da calor y lo alimenta. La mujer levanta un hogar en la mitad de la barbarie fuera de todo progreso, técnica o comodidad moderna. No es su esposo, ni su padre, ni su hijo: es los tres al mismo tiempo. Desde este escenario radical Mistral muestra la debilidad del Padre, del orden institucional, y marca su límite en el espacio de la maternidad.

Aquí la sangre pierde su peso. La 'maternidad' no es una función que pueda definirse en referencia al orden natural. Mistral observa la función de la 'maternidad' vinculada a la posición del sujeto respecto del resto de los miembros del orden social, estar en la frontera entre la civilización y la barbarie animal, pero no desde el lugar del poder, sino representando el silencio del oprimido. Declara en un texto de 1927, "la mujer no tiene colocación natural [ . . ], sino cerca del niño o la criatura sufriente, que también es infancia, por desvalimiento" ("Trabajo II" 257). Mistral desplaza el anclaje natural de la maternidad. Cambia el hijo biológico por el desvalido. Esta desviación respecto del fin simbólicamente determinado constituye el acto perverso.

En términos políticos, la 'maternidad' mistraliana, asumiendo la forma de la perversión femenina, es capaz de enfrentar la negatividad mediante una lógica de equivalencias similar a la del populismo. Pero si en el populismo un grupo de demandas sociales frustradas posicionan el significante vacío en el lugar del objeto para generar la frontera en lo social, en Mistral, en cambio, el significante vacío ocupa el lugar del sujeto. Una Antígona busca honrar la memoria de un muerto; la otra, se crucifica ella misma en un significante. La madre, en este caso, se somete al orden institucional. Su sumisión, sin embargo, no se equipara al neurótico castrado, quien habita sin reparos las reglas del orden social vigente. Esta sumisión es perversa. El Padre del perverso no es el del orden simbólico, sino un Padre imaginario. 
El Padre de la perversa mistraliana es el Padre de la utopía. Resigna su posición, pero exige reformas. Las demandas de la cadena de equivalencias se reagruparían en torno a una demanda particular, pero con la finalidad de crear una comunidad con una nueva institucionalidad. La crítica mistraliana no pretende declarar la completa suspensión de la institucionalidad, sino indicar la debilidad de base que toda institución porta consigo. Mistral reconviene a aquellos grupos que demandando reivindicaciones sociales, disfrutan en ver el mundo actual en llamas, adoptando la misma forma del discurso de sus más fervientes enemigos, sometiendo la acción colectiva a lograr la Revolución prometida y no transformar las prácticas cotidianas. Confiesa en el Diario íntimo, "yo no puedo caer en ese nihilismo de nuestros izquierdistas de negar a todos y de volver la cara al Juicio Final como la única solución” (151). Dirá Mistral que la organización política de las mujeres debe emprender la lucha con la meta de "humanizar el Estado; y hacer así esa red de intereses y de amor que es una raza" (“Organización de las mujeres" 69). En este sentido, la renuncia a situar el orden institucional en la posición del enemigo lo constituye en la trinchera en la que la lucha social se encarna verdaderamente. La demanda particular de esta lógica de articulación será la exigencia de reformas políticas.

Claramente, la desventaja de la articulación mistraliana está en la agencia reducida que le otorga a la mujer en la vida social. Mistral cree que el hombre ha de ser el encargado de la guía política de la República y la mujer de los trabajos que tengan relación con 'el niño' — significante del desvalido-. Pero la sumisión adopta la forma de una amenaza. La forma específica de la perversión permite poner al servicio de las reivindicaciones políticas de la mujer la condición opresiva de la función materna. Sin la función específica de la 'maternidad' manteniendo el límite de lo civilizado, el orden institucional sería arrojado a la muerte. Negar la participación de la mujer en la vida política, hace del orden institucional su propio verdugo. Así, es capaz de afirmar "la forma del patriotismo femenino es la maternidad perfecta” (Lecturas XVIII). 
Mistral invita a asumir una posición fuerte respecto de las reformas del sistema político chileno, en conexión con las luchas concretas del feminismo sufragista de la época.

El voto femenino es cosa para discutirla en lenguaje de derecho. En sistema de sufragio universal o restringido, desde que la revolución que llaman grande clavó con picota rotunda el principio de representación popular, quedó por entendido que el voto correspondía... al género humano. Discutir sobre la extensión de este derecho no es serio y cuando no prueba malicia prueba estupidez. ("Voto" 261)

La perversión reconfigura el relato de Fiol-Matta. El sujeto perverso es estructuralmente queer. En el caso de Mistral, la alianza con el orden simbólico tomaría la forma de una maternidad adaptada a los proyectos nacionales concretos. Pervierte el significante hasta equiparar el hijo al desvalido. Por eso, la transición de un discurso a otro está determinada por la articulación contingente de la maternidad. La madre es el soporte de la fantasía del Estado. De ahí que la subjetividad queer de Mistral resulte tan seductora para el poder. Además, permite dar cuenta del goce, ya que lejos de un ocultamiento paranoico, Mistral juega con la visibilidad de su identidad queer, a través de la formulación de fantasías y citas al canon, juego que le permite vivir al amparo económico del Estado sin asumir la castración de una familia heteronormativa consumada. Antígona materna es una de esas voces desde la que su política se hace visible. No es un discurso de una salvación absoluta, sino una lucha constante por fundar ciudadanía. A la sombra de la devastación y los totalitarismos, Mistral vuelve a creer en la organización social y la acción colectiva. Evoca la presencia del Padre arruinado, "Viejo Rey, dónde ya no puedas háblame" (22); lo ve infantil, débil, desvalido, y se entrega perversamente a la esperanza, "si no logras dormir, puedo cargarte/ el cuerpo nuevo que llevas ahora" (28-9). 


\section{Bibliografía}

Butler, Judith. Antigone's Claim: Kinship between life and death. New York: Columbia University Press, 2000.

Eagleton, Terry. Trouble with Strangers. Chichester: Wiley-Blackwell, 2009.

Fink Bruce. "Perversion." Perversion and the Social Relation. By Molly Anne.

Halperin, David. Saint Foucault: Towards a Gay Hagiography. Oxford: OUP, 1995.

Rothenberg, Dennis A. Foster, and Slavoj Zizek. Durham: Duke UP, 2003.

Kristeva, Julia. "Stabat mater." Historias de amor. 1983. México, D.F.: Siglo veintiuno; Madrid: Siglo veintiuno de España; Buenos Aires: Siglo veintiuno Argentina; Bogotá: Siglo veintiuno de Colombia, 1987. 209-34.

Mistral, Gabriela. “Antígona.” Lagar II. Santiago: DIBAM, 1991.

---. Bendita sea mi lengua. Diario íntimo. Ed. Jaime Quezada. Santiago: Planeta, 2009.

---. Lecturas para mujeres. 1967. 9na ed. México, D.F.: Porrúa, 2005.

---. Motivos de San Francisco. 1967. Antología. Real Academia Española. Ed. Con. Madrid: Santillana, 2010. 568-74.

---. “Organización de las mujeres.” 1925. Escritos políticos. Ed. Jaime Quezada. México, D.F: Fondo de Cultura Económica; Santiago: Fondo de Cultura Económica Chile, 1995. 66-74.

---. "Sobre la mujer chilena." 1946. Escritos políticos. Ed. Jaime Quezada. México, D.F: Fondo de Cultura Económica; Santiago: Fondo de Cultura Económica Chile, 1995. 61-5.

---. "Sobre una nueva organización del trabajo (I)." 1927. Escritos políticos. Ed. Jaime Quezada. México, D.F: Fondo de Cultura Económica; Santiago: Fondo de Cultura Económica Chile, 1995. 253-6. 
CATEDRAL TOMADA: Revista de crítica literaria latinoamericana / Journal of Latin American Literary Criticism Rodrigo Fernando del Río

---. "Sobre una nueva organización del trabajo (II)."1927. Escritos políticos. Ed. Jaime Quezada. México, D.F: Fondo de Cultura Económica; Santiago: Fondo de Cultura Económica Chile, 1995. 257-60.

---. "El voto femenino." 1928. Escritos políticos. Ed. Jaime Quezada. México, D.F: Fondo de Cultura Económica; Santiago: Fondo de Cultura Económica Chile, 1995. 261-6.

Lacan, Jacques. El seminario de Jacques Lacan. Libro 7. La ética del psicoanálisis 1959-1960. 1964. Ed. Jacques Alain Miller. Trad. Diana S. Rabinovich. Buenos Aires: Paidós, 1988.

Laclau, Ernesto. On Populist Reason. London, New York: Verso, 2005.

Laclau, Ernesto. "Populism: What's in a Name." Populism and the Mirror of Democracy. Ed. Francisco Panizza. London, New York: Verso, 2005. 32-49

Sófocles. Antígona. Tragedias. Trad. A. Alamillo. Madrid: RBA, 2006.

Zizek, Slavoj. In Defense of Lost Causes. London, New York: Verso, 2008.

(oc) $\mathbf{E Y - N C - M D}$ ULIS D-Sorle
This work is licensed under a Creative Commons Attribution-Noncommercial-No Derivative Works 3.0 United States License.

This site is published by the University Library System, University of Pittsburgh as part of its D-Scribe Digital Publishing Program and is cosponsored by the University of Pittsburgh Press. 